\title{
Ecological dominance of Lessonia nigrescens (Phaeophyta) in central Chile
}

\author{
F. P. Ojeda* and B. Santelices \\ Departamento de Biología Ambiental y de Poblaciones, Facultad de Ciencias Biológicas, Pontificia Universidad Católica \\ de Chile, Casilla 114-D, Santiago, Chile
}

\begin{abstract}
Experimental removal of various types of dominant canopies have resulted in predictable patterns of competitive hierarchies among algae in intertidal and subtidal communities. However, few attempts have been made to distinguish functionally different groups of algae in these communities. The intertidal/subtidal boundary of exposed rocky habitats in central Chile is numerically dominated by the kelp Lessonia nigrescens. When the kelp is absent, 2 other algal formations can be found at this intertidal level. In vegetational openings surrounded by individuals of $L$. nigrescens and in the absence of large grazers, large patches of Gelidium chilense occur. In vegetational openings with abundance of grazers, patches of calcareous algae and bare rock are normally found. Through experimental manipulation we evaluate the ecological changes of the understory algal assemblages following removal of the numerically dominant $L$. nigrescens and confirm that, with minor differences the 3 functional groups of algae distinguished elsewhere ('canopy forming', 'fugitive' and 'obligated understory') also occur here. By experimental removal at different seasons and in presence or absence of sea urchins we explain the occurrence of the 2 algal formations found in areas devoid of kelp.
\end{abstract}

\section{INTRODUCTION}

Plants rather than animals are the numerically dominant lower seashore organisms in temperate latitudes (Connell, 1975). Kelps are often among the most important components in these assemblages, sometimes exerting competitive control of the abundance and distribution of other species (Dayton, 1975a). These canopy species apparently succeed in competitively dominating the light resource and their removal is normally followed by blooms of fugitive species and disappearance of obligated understory species (Dayton, 1975a).

In recent years, experimental removal of various types of dominant canopies have resulted in the establishment of predictable patterns of competitive hierarchies among algae in intertidal and subtidal communities (Dayton, 1975b; Foster, 1975; Pearse and Hines, 1979; Duggins, 1980; Lubchenco, 1980; Moreno and Sutherland, 1982; Reed and Foster, in press). All these studies have documented increments in the second and third algal strata following canopy removal

\footnotetext{
- Present address: Departments of Botany and Zoology, University of Maine, Orono, Maine 04469, USA
}

but few attempts have been made to distinguish functionally different groups of algae as Dayton (1975a) did with the algal assemblages on the Washington coastline. Most of the above studies have concentrated on describing algal responses of the species which normally bloom after canopy removal, but only Lubchenco's (1980) study has recognized a species as possibly 'obligated understory' (sensu Dayton, 1975a) in the low intertidal algal assemblages of New England. Ecological responses shown by species of tropical crustose coralline algae (Littler and Doty, 1975), however, indicate that some of them also might be obligated understory species.

The intertidal-subtidal boundary of exposed rocky habitats in central Chile is numerically dominated by the kelp Lessonia nigrescens (Santelices et al., 1980; Cancino and Santelices, 1981). When the kelp is absent, 2 other algal formations can be found at this intertidal level. In vegetational openings surrounded by individuals of $L$. nigrescens and in the absence of large grazers - such as the chiton Acanthopleura echinata (Barnes) or the sea urchin Tetrapygus niger (Molina) - large patches of Gelidium chilense (Montagne) Santelices and Montalva can be found. In vegetational openings with abundance of grazers, patches 
of calcareous crustose algae and bare rock normally occur. In this study we experimentally evaluate the ecological changes of the understory algal assemblages following the removal of the numerical dominant $L$. nigrescens Bory. In so doing we explain the occurrence of the alternative equilibrium states (sensu Sutherland, 1974) in the L. nigrescens belt as depending on competition and grazing.

\section{MATERIALS AND METHODS}

\section{Study site}

The study was carried out on wave exposed, almost vertical, rocky walls ( $65^{\circ}$ slope) in the vicinity of Caleta Los Molles (32 $15^{\prime} \mathrm{S} ; 71^{\circ} 30^{\prime} \mathrm{W}$ ) (Fig. 1). The zonation pattern found in this area is quite uniform and representative of wave exposed rocky intertidal habitats

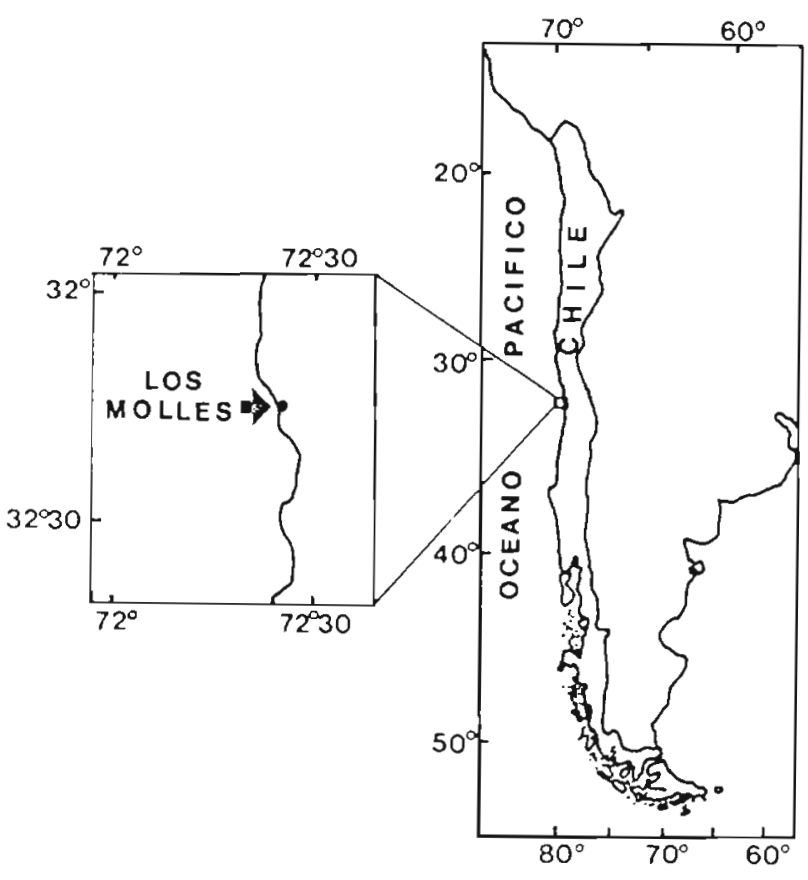

Fig. 1. Map of Chile showing location of study site

in central Chile (Santelices et al, 1980, 1981). The dominant feature is a belt of Lessonia nigrescens with scattered individuals of Durvillea antarctica (Chamisso) Hariot extending from $0.5 \mathrm{~m}$ above mean low water level (MLWL) down to $4 \mathrm{~m}$ below MLWL. Extended, flat colonies of the crustose, non-calcareous chlorophyte Codium dimorphum Svedelius and dense, cushion-like aggregations of small tufts of Gelidium chilense occupy the $100 \mathrm{~cm}$ immediately above. Spreading, pink colonies of the crustose coralline Mesophyllum sp. extend from the level of the holdfasts of Lessonia nigrescens down to 4 to $5 \mathrm{~m}$ below MLWL. Large-sized grazers such as the chiton Acanthopleura echinata (Barnes), sea urchins such as Tetrapygus niger (Molina) or Loxechinus albus (Molina), or large individuals of Tegula atra (Lesson) can be found occurring on the pink Mesophyllum but removed from the reach of stipes and fronds of $L$. nigrescens.

\section{Experimental treatments}

To evaluate the effects of removal of Lessonia nigrescens on the understory algal assemblages, eight $4 \times 2 \mathrm{~m}$ areas were cleared of all $L$. nigrescens individuals. Four areas were cleared in May, 1979 (winter), whereas the other four were cleared in Jan, 1980 (summer).

Large grazers are infrequent within consolidated belts of Lessonia nigrescens. The continuous movement of the large and flexible stipes of the kelp in these wave exposed habitats apparently limits the number of grazers. They are capable of reaching beneath the $L$. nigrescens canopy only at high tide when the water movement is reduced and the kelp stipes and fronds are at an almost right angle in reference to the substrate. In areas devoid of kelps, however, no limitation apparently exists for the movement of these grazers and they concentrate there in high densities. To evaluate the effects of herbivory in the colonization process following removal of $L$. nigrescens, 200 adult specimens of the sea urchin Tetrapygus niger were introduced in 2 of the 4 experimental plots cleared in May and in 2 of those cleared in Jan. The plants of $L$. nigrescens around these plots were pruned for reducing interference with the sea urchins. However, the plants were maintained in order to limit migration of grazers in and out the experimental plot. The other 2 areas cleared in May and Jan were maintained free of grazers, manually removing any individual found inside the plots.

All experimental areas were monitored monthly. Two vertical levels were distinguished and permanently marked at each experimental area (Fig. 2). The 'attachment level' was defined as the level of attachment of the holdfasts of Lessonia nigrescens. The 'under-canopy' level was located underneath the fronds of $L$. nigrescens. Cover values of algae found at each of these levels in each plot were measured using four $0.25 \mathrm{~m}^{2}$ iron quadrats with 81 intercept points. All data were then angular-transformed for statistical analysis (Sokal and Rohlf, 1969). 


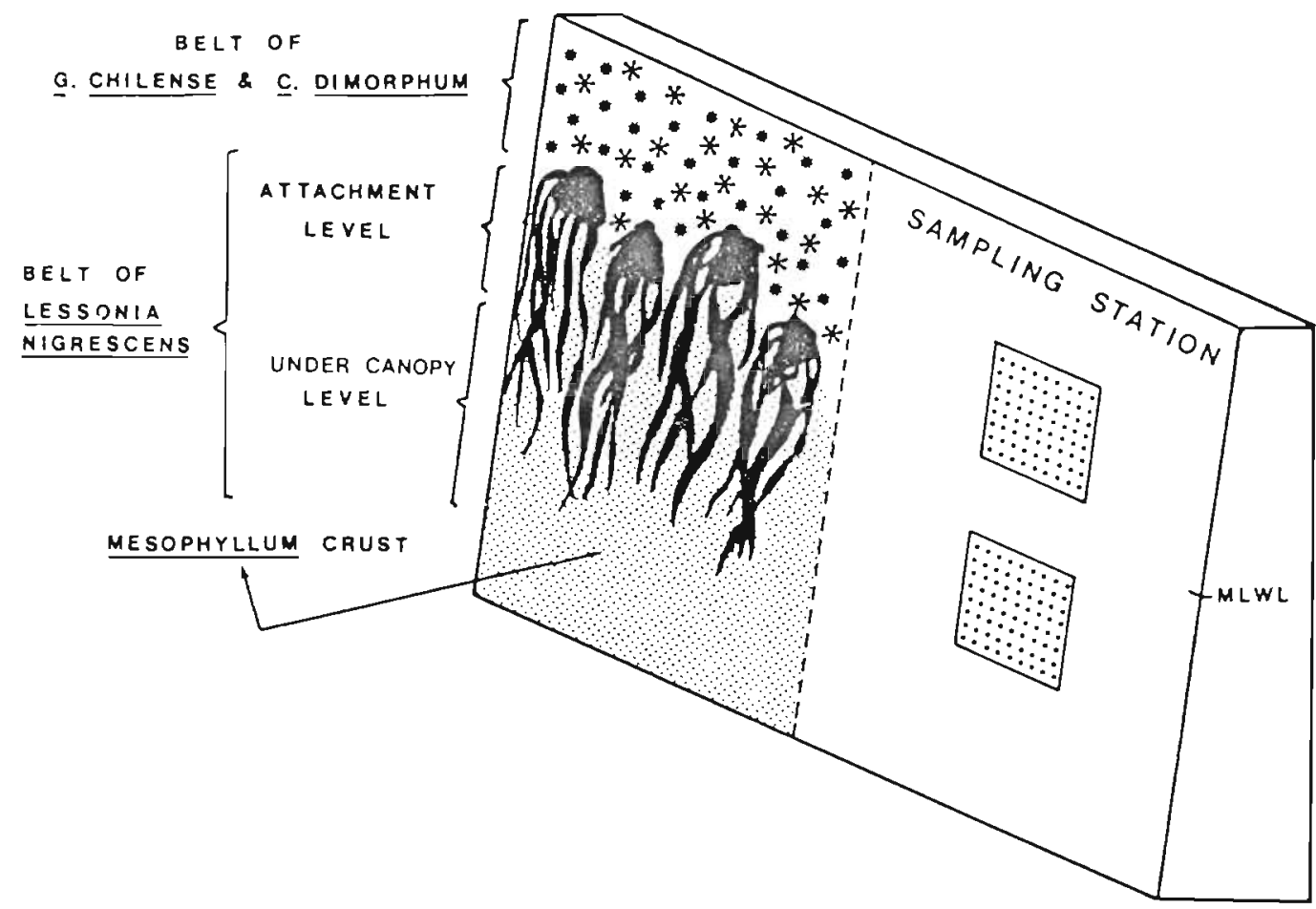

Fig. 2. Intertidal-subtidal boundary in a rocky exposed habitat of central Chile and the 2 vertical sampling stations used

\section{RESULTS}

\section{Removal of Lessonia nigrescens in absence of Tetrapygus niger}

\section{Winter removal}

The rocky surface cleared during May by removal of Lessonia nigrescens at the attachment level was rapidly covered by Ulva rigida and Gelidium chilense (Fig. 3). These 2 species existed among the holdfasts of L. nigrescens with pre-removal cover values of 10 and $5 \%$, respectively. Their values rose to 60 and $30 \%$, respectively, 2 mo after kelp removal.

The first juveniles of Lessonia nigrescens started appearing by the end of Jul 1980. During Aug, they covered close to $50 \%$ of the rocky surface both at the attachment level and at the undercanopy level. Cover values of these juveniles steadily increased as they grew, reaching $100 \%$ cover by Mar 1981. Simultaneously, cover values of Ulva rigida and Gelidium chilense steadily decreased, reaching values close to $0 \%$. It was frequent to see newly settled juveniles covering $G$. chilense by growth of their massive holdfasts.

Observations in the non-removal areas indicated no major changes during the 15 mo of study at the attachment level. Data indicated $100 \%$ cover of Lessonia nigrescens. Ulva rigida and Gelidium chilense did occur among the holdfasts of $L$. nigrescens but the presence of the attachment surface of the kelp did not allow us to assess quantitatively their cover values. Field estimates, however, indicated cover values of less than $10 \%$ for each of the 2 species. The increment. in cover shown by $U$. rigida and $G$. chilense during Jun-Jul did not occur in the non-removal areas.

Vegetational changes in the under-canopy area after winter removal of Lessonia nigrescens were slightly different (Fig. 3). Most of the pre-removal surface underneath the canopy of $L$. nigrescens was covered by a pink crust of Mesophyllum sp. After removal of the kelp canopy, cover values of Mesophyllum sp. steadily decreased reaching close to $30 \%$ cover by Sep. Field observations indicated that the crustose coralline first became bleached and then reduced its representation in the experimental area. This seems to be a result produced by increased light intensity reaching the crust surface, coupled with desiccation of the crust during low tides. Simultaneously, Ulva rigida, Codium dimorphum and Gelidium chilense increased their cover values. The first 2 species showed a patchy occurrence during the first months of the experiment whereas $G$. chilense occurred as the most permanent member.

Juveniles of Lessonia nigrescens also appeared at the under-canopy level in Aug 1980. However, their 
REMOVAL AREA

ATTACHMENT LEVEL
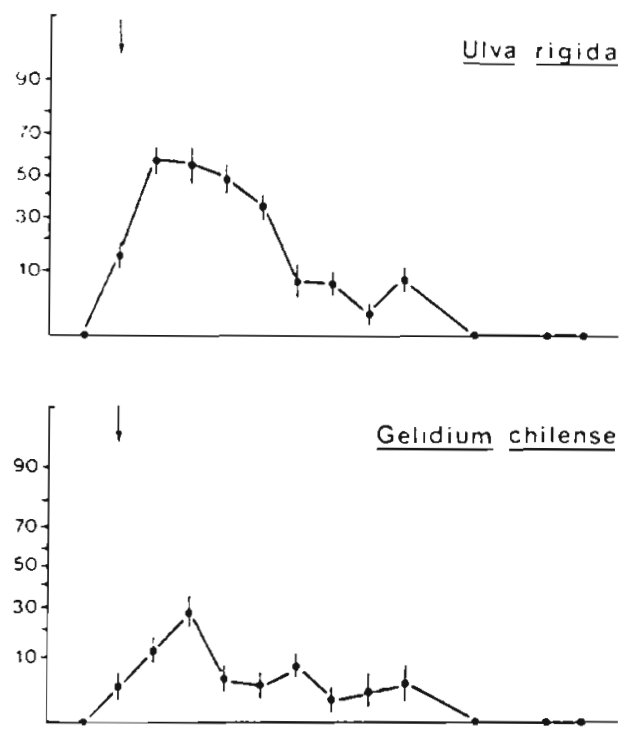

$\simeq$

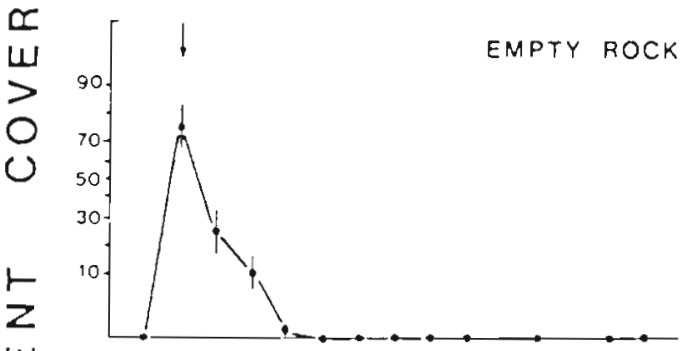

w

U

$\propto$

$w$

ㅇ
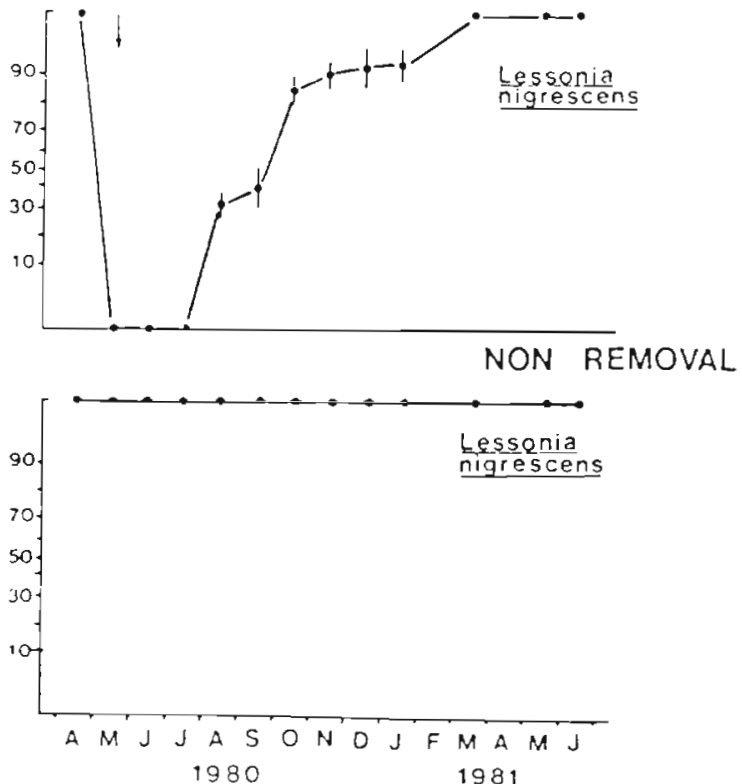

UNDER CANOPY LEVEL

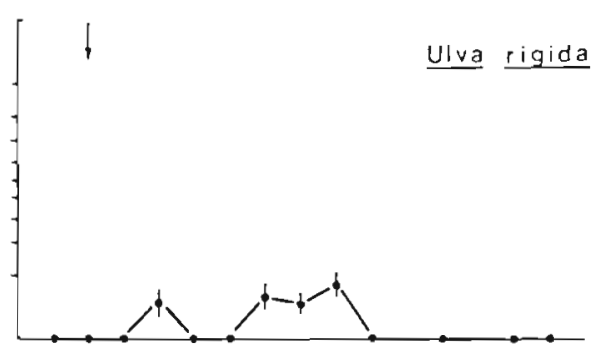

Gelidium chilense
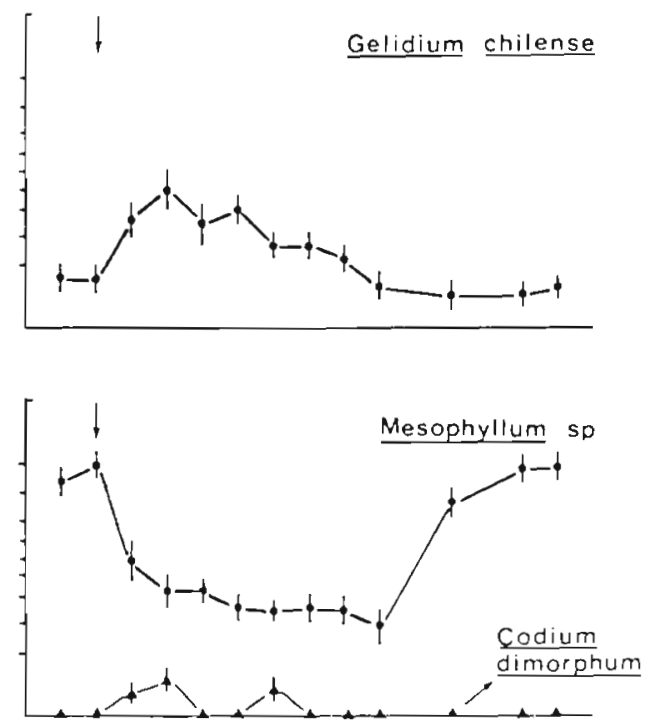

Lessonia

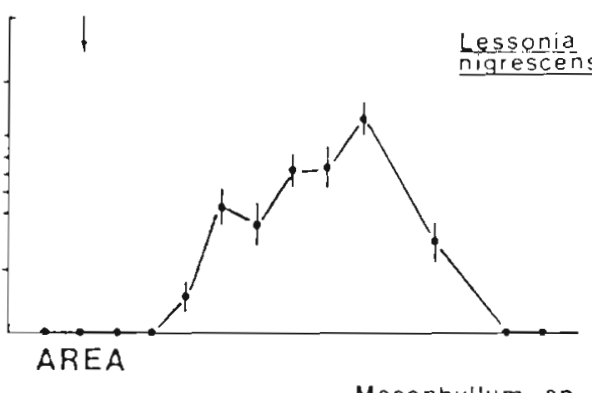

Mesophyllum sp

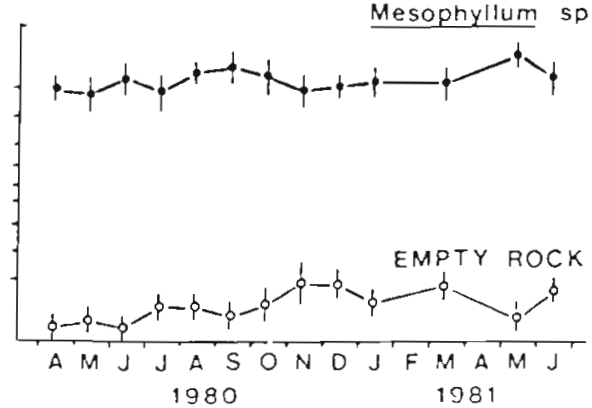

Fig. 3. Changes in algal-species importance at 2 vertical levels following winter removal of Lessonia nigrescens in the absence of grazers (points and bars refer to $\overline{\mathrm{X}}$ and $2 \mathrm{SE}$, respectively). Arrows indicate $L$. nigrescens removals 
cover values increased only until Jan 1981. By Feb, juveniles of $L$. nigrescens settled in the attachment zone were long enough as to overshade and rub the juveniles settled in the under-canopy level. Most of the juveniles in the under-canopy level disappeared by May 1981. By this time, Mesophyllum sp. recovered its $90 \%$ pre-removal cover value under the shade of the $L$. nigrescens plants.

Comparison with events occurring in the nonremoval plots at this vertical level indicates that
Mesophyllum sp. maintains cover values close to $90 \%$ during most of the year. No other algae showed significant cover values at this shore level.

\section{Summer removal}

The course of events following summer removal of Lessonia nigrescens (Fig. 4) is quite similar in both attachment and under-canopy levels. Summer removal

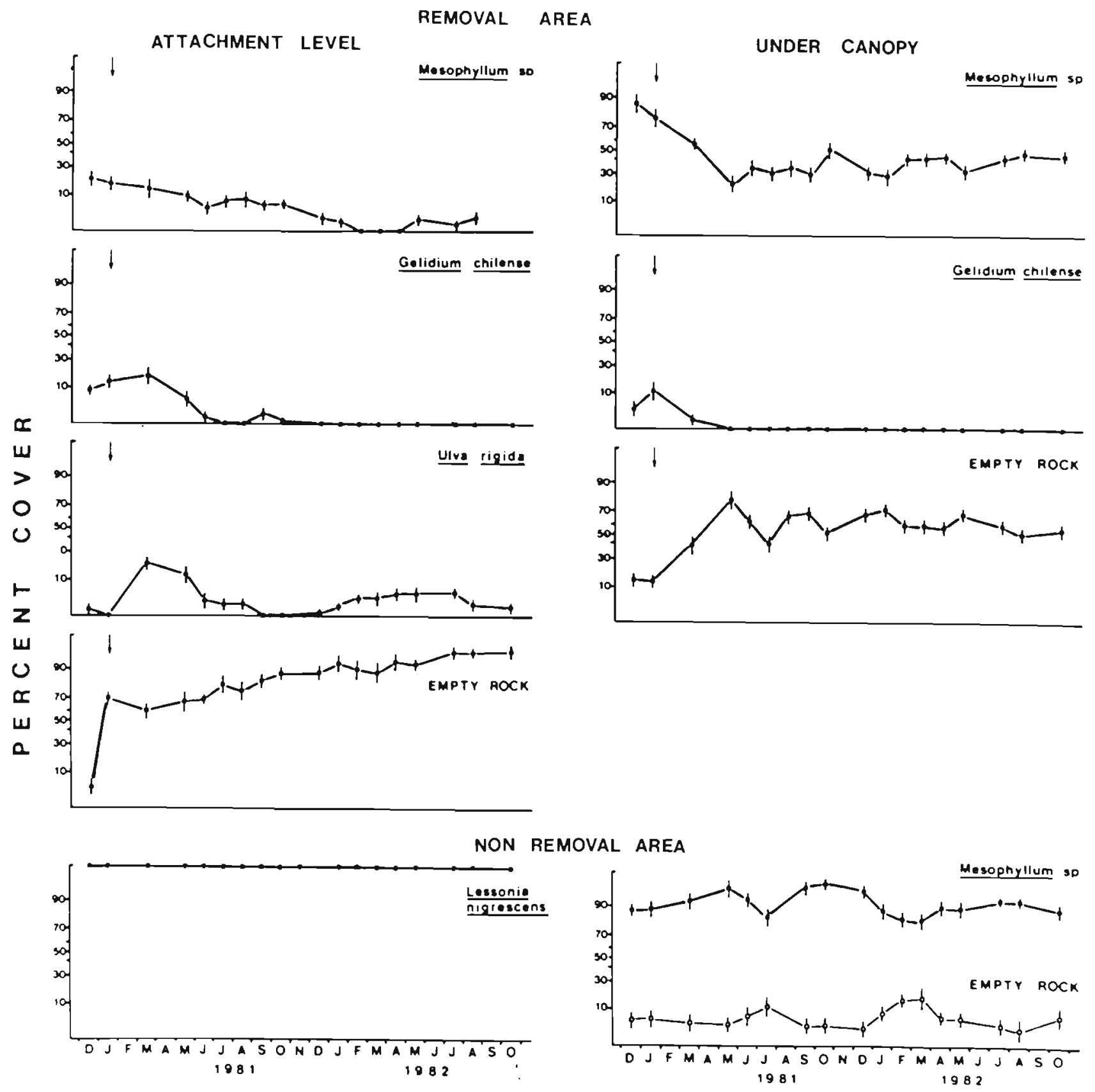

Fig. 4. Changes in algal-species importance at 2 vertical levels following summer removal of Lessonia nigrescens in the absence of grazers 
of L. nigrescens is followed by drastic reduction of Mesophyllum sp., especially at the under-canopy level, and by a steady increment of the cover values of Gelidium chilense rising from $15 \%$ in Jan 1981 to 70 to $90 \%$ by Oct 1982 . Ulva rigida had in these plots cover values of less than $40 \%$ with scattered summer blooms especially at the under-canopy level. No recruitment of juveniles of $L$. nigrescens occurred in these experimental areas during our 21 mo experimental study. Consequently, a dense monoculture of $G$. chilense persisted in these plots up to Oct 1982, when the study was terminated.

Data gathered from plots with no removal of Lessonia nigrescens indicated a pattern of events similar to the one already described for the winter nonremoval plots. At the attachment level most of the substrate was covered by holdfasts of $L$. nigrescens with Mesophyllum sp. being the only algal species found underneath their shade.

\section{Removal of Lessonia nigrescens in the presence of Tetrapygus niger}

Winter removal

Winter removal of Lessonia nigrescens followed by addition of Tetrapygus niger resulted in a reduction of algal cover, and in a significant increment of bare rock (Fig. 5). This reduction was caused by decreased cover values of Mesophyllum sp., probably due mainly to bleaching and desiccation. Also there was a reduction of cover values or complete absence of Codium dimorphum, Ulva rigida and Gelidium chilense; and absence of settlement or growth of juveniles of $L$. nigrescens probably due to grazing by the sea urchin.

\section{Summer removal}

Results obtained after summer removal of Lessonia nigrescens in the presence of Tetrapygus niger are similar to those obtained after winter removal (Fig. 6). Presence of $T$. niger does not allow any algal species to increase their cover values or monopolize the substrate.

\section{DISCUSSION AND CONCLUSIONS}

Although the wave exposed intertidal and subtidal marine communities in Central Chile appear simple in terms of structure and species richness (Santelices, $1980,1981)$, the 3 functional groups distinguished by Dayton (1975a) in the more complex Washington com- munities also occur here. Lessonia nigrescens is the canopy species, a competitive dominant whose removal is followed by drastic changes in the understory algal assemblage. The crustose Mesophyllum sp. appears to be the only obligated understory species in this assemblage, whereas Ulva rigida and Gelidium chilense (and to a lesser extent Codium dimorphum) react as 'fugitive species' (sensu Dayton, 1975a) increasing their cover values after removal of $L$. nigrescens.

The response shown by the understory algal assemblage in Central Chile, however, has some minor differences with what Dayton (1975a) found in the North Pacific. The obligated understory species, Mesophyllum sp., does not completely disappear after removal of Lessonia nigrescens, because of its tolerance to increased light intensity. On the other hand, Gelidium chilense and Codium dimorphum, which behave as fugitive species, are perennial algae typical of the intertidal levels just above the $L$. nigrescens belt (Montalva and Santelices, 1981; Santelices, 1981). When newly settled juveniles of $L$. nigrescens appeared in Aug 1980, they overgrew, shaded and later covered with their massive holdfasts the thalli of $G$. chilense and of all other algal species. These results suggest that the lower limit of $G$. chilense in these assemblages may be determined by competitive interactions with $L$. nigrescens. Our results indicate, in addition, that the outcome of these interactions is strongly dependent on the periodicity of algal reproduction. In Central Chile, G. chilense is reproductive all year round (Montalva and Santelices, 1981) whereas juvenile settlement of $L$. nigrescens occurs only from Aug to Nov. Thus, removal of $L$. nigrescens during Dec-Jan allows for 4 to 5 mo of invasion and growth of $G$. chilense, free from its competitive dominant. The settlement of $L$. nigrescens expected to occur in Aug did not occur in our experiments apparently due to monopolization of the primary substrate by $G$. chilense. These results indicate the importance of interference interactions between an adult plant and a morphologically similar juvenile form of a morphologically different adult plant. Up to now, only Lubchenco (1980) has reported a similar phenomenon when studying interactions between Chondrus and Fucus in New England but it seems likely that this phenomenon is widespread especially among kelps which have long life histories with several morphologically different stages.

As stated previously, it is quite uncommon to find naturally large patches of Gelidium chilense in the subtidal-intertidal fringe of Central Chile such as those found after our summer experimental removal. Storms strong enough to remove whole Lessonia nigrescens plants are much more common in winter, when 


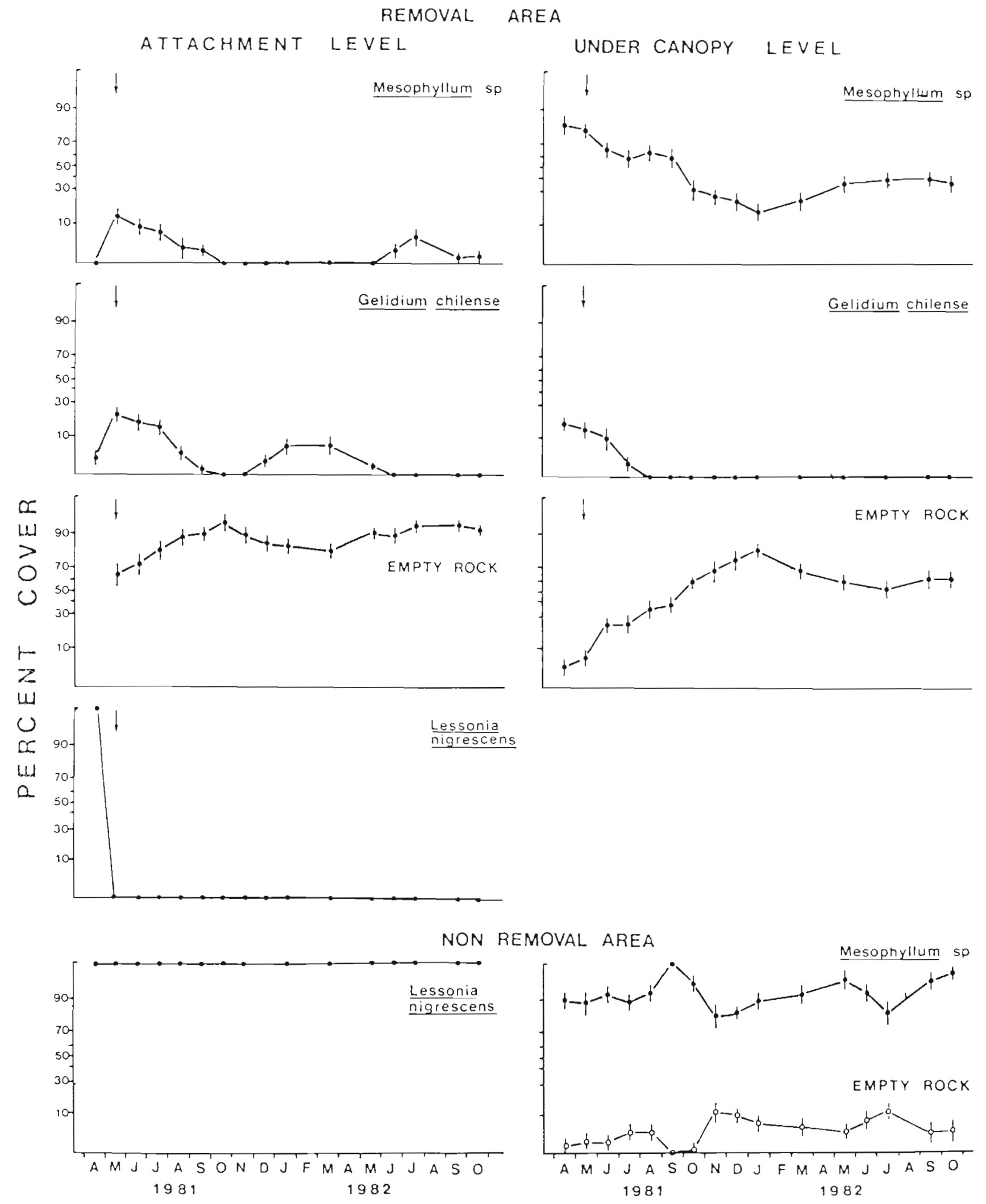

Fig. 5. Changes in algal-species importance at 2 vertical levels following winter removal of Lessonia nigrescens in the presence of grazers 


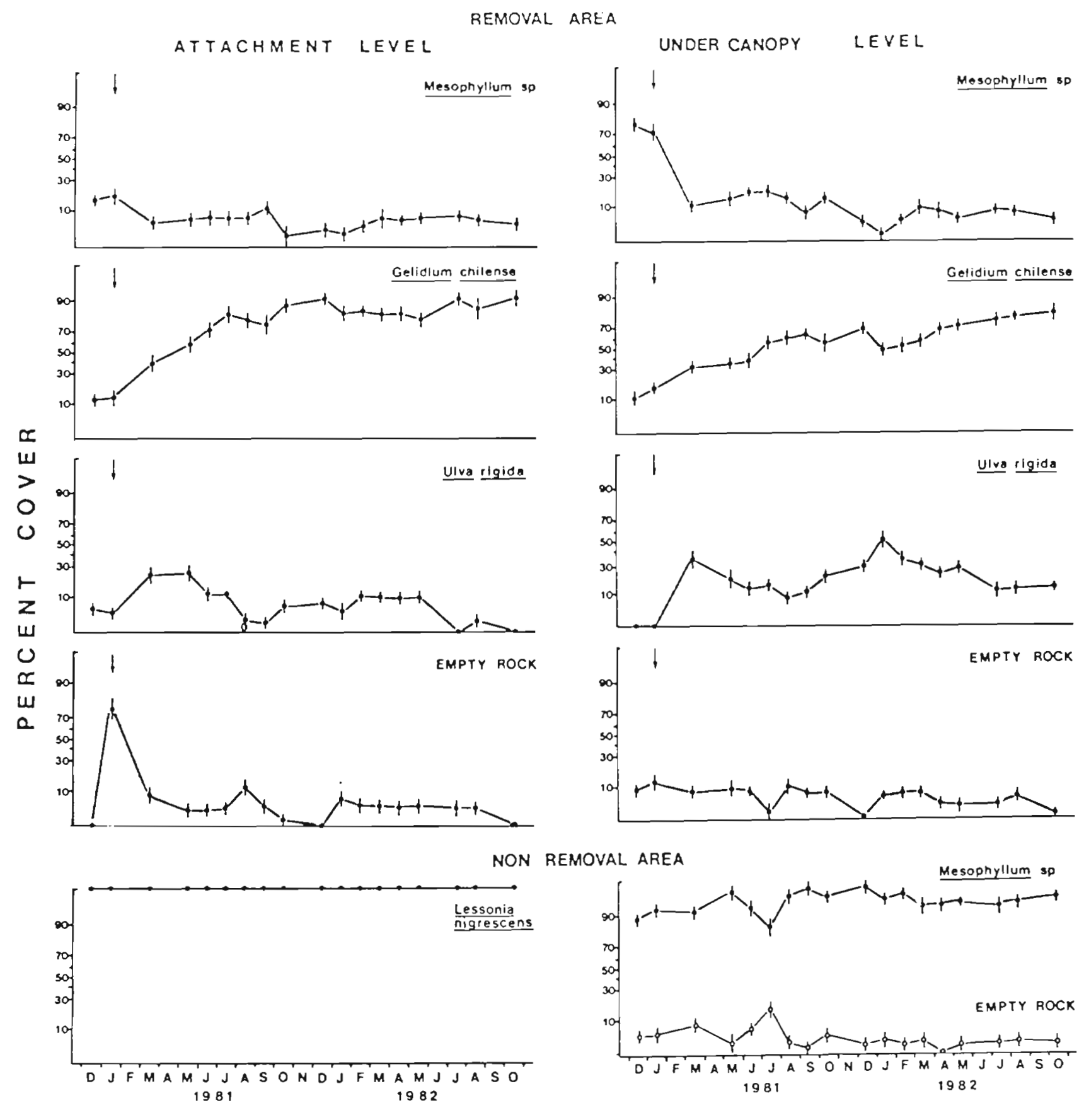

Fig. 6. Changes in algal-species importance at 2 vertical levels following summer removal of Lessonia nigrescens in the presence of grazers

L. nigrescens has maximum fertility. The expected outcome of the recolonization process following those disturbances should be similar to the one started with the removal experiments performed in winter. In consequence, the reproductive pattern of $L$. nigrescens may represent an adaptive response to seasonally predictable patches of substrate produced by storms. Similar situations have been documented for Laminaria
(Markham, 1973) and Hedophyllum (Dayton, 1975a) in the Northern Hemisphere.

The sea urchin Tetrapygus niger has a strong effect on the colonization process occurring after removal of Lessonia nigrescens. Only the encrusting calcareous algae Mesophyllum sp. persists in the presence of $T$. niger. Nevertheless, this grazing effect is seen only in large areas previously devoid of $L$. nigrescens plants. 
The pronounced whiplash effect strong movement of fronds and stipes of L. nigrescens on the sea urchins, the fast growth rate of $L$. nigrescens and the large size reached, all seem to constitute adaptations limiting herbivory as has been described for kelps elsewhere (Connell, 1975; Dayton, 1975a).

Acknowledgements. The authors appreciate the help provided by Julio Vásquez, Isabel Meneses, Juan Correa and Daniel Moraga in the field work, and the economic support of Subsecretaría de Pesca, Ministerio de Economía, Fomento y Reconstrucción. Criticisms and comments by P. Dayton, J. Geaghan, F. Jaksić, J. McLachlan and R. Vadas are acknowledged with gratitude.

\section{LITERATURE CITED}

Cancino, J., Santelices, B. (1981). The ecological importance of kelp-like holdfasts as a habitat of invertebrates in central Chile. II. Factors affecting community organization. Proceedings of International Seaweed Symposium, 10, Sweden, p. 241-246

Connell, J. H. (1975). Some mechanisms producing structure in natural communities: a model and evidence from field experiments. In: Cody, M. L., Diamond, J. M. (ed.) Ecology and evolution of communities. Belknap Press of Harvard University, Cambridge, p. $460-490$

Dayton, P. K. (1975a). Experimental evaluation of ecological dominance in a rocky intertidal community. Ecol. Monogr. 45: $137-159$

Dayton, P. K. (1975b). Experimental studies of algal canopy interactions in a sea otter dominated kelp community at Amchitka Island, Alaska. Fish. Bull. U.S. 73: 230-237

Duggins, D. O. (1980). Kelp beds and sea otters: an experimental approach. Ecology 61: 447-453

Foster, M. S. (1975). Algal succession in a Macrocystis pyrifera forest. Mar. Biol. 32: 313-329
Littler, M. M., Doty, M. S. (1975). Ecological components structuring the seaward edges of Tropical Pacific reefs: the distribution, communities and productivity of Porolithon. J. Ecol. 63: 117-129

Lubchenco, J. (1980). Algal zonation in the New England rocky intertidal community: an experimental analysis. Ecology 61: 333-344

Markham, J. W. (1973). Observations on the ecology of Laminaria sinclairii (Harvey) Farlow, Anderson et Eaton. Syesis 1: 125-131

Montalva, S., Santelices, B. (1981). Interspecific interferences among species of Gelidium from Central Chile. J. exp. mar. Biol. Ecol. 53: 77-88

Moreno, C. A., Sutherland, J. P. (1982). Physical and biological processes in a Macrocystis pyrifera community near Valdivia, Chile. Oecologia (Berl.) 55: 1-6

Pearse, J. S., Hines, A. H. (1979). Expansion of a Central California kelp forest following the mass mortality of sea urchins. Mar. Biol. 51: 83-91

Reed, D. C., Foster, M. S. (in press). The effects of canopy shading on algal recruitment and growth in a giant kelp forest. Ecology

Santelices, B. (1980). Phytogeographic characterization of the temperate coast of Pacific South America. Phycologia 19: $1-12$

Santelices, B. (1981). Perspectiva de investigación en estructura y dinámica de comunidades intermareales rocosas de Chile Central. I. Cinturones de macroalgas. Medio Ambiente 5: 175-189

Santelices, B., Castilla, J. C., Cancino, J., Schmiede, P. (1980). Comparative ecology of Lessonia nigrescens and Durvillaea antarctica (Phaeophyta) in Central Chile. Mar. Biol. 59: $119-132$

Santelices, B., Montalva, S., Oliger, P. (1981). Competitive algal community organization in exposed intertidal habitats from Central Chile. Mar. Ecol. Prog. Ser. 6: $267-276$

Sokal, R. R., Rohlf, F. J. (1969). Biometry. W. H. Freeman, San Francisco, California

Sutherland, J. P. (1974). Multiple stable points in natural communities. Am. Nat. 108: 859-873 